\title{
N2 Sleep Phase Duration
}

National Cancer Institute

\section{Source}

National Cancer Institute. N2 Sleep Phase Duration. NCI Thesaurus. Code C154869.

The length of time of N2 sleep. 